\title{
IMPLEMENTASI NIRMANA PADA FOTOGRAFI PORTRAITURE 3D ANAGLYPH
}

\author{
Daniar Wikan Setyanto ${ }^{1}$, Puri Sulistiyawati², Erisa Adyati Rahmasari ${ }^{3}$ \\ 1,2,3 Program Studi Desain Komunikasi Visual, Fakultas IImu Komputer, Universitas Dian Nuswantoro \\ daniarwikan@dsn.dinus.ac.id ${ }^{1}$, puri.sulistiya@gmail.com², erisa.adyati@dsn.dinus,ac,id ${ }^{3}$
}

\begin{abstract}
Abstrak
Implementasi teknologi 3D saat ini lebih banyak digunakan di dunia perfilman dan animasi, padahal teknologi tersebut memiliki potensi untuk dikembangkan dalam fotografi, khususnya fotografi 3D. Sampai saat ini masih sedikit fotografer yang mendalami dan tertarik untuk melakukan eksperimen. Fotografi 3D menyimpan potensi untuk dikembangkan karena implementasi 3D dapat membuat media foto tersebut menjadi sangat unik. Fotografi sendiri merupakan salah satu dari bidang ilmu pengetahuan, teknologi dan seni (IPTEKS), oleh karena itu ilmu fotografi seharusnya bergerak dinamis mengikuti perkembangan teknologi. Melalui penelitian yang mengarah pada eksperimental fotografi dan citra 3D diharapkan dapat memberikan kontribusi kebaharuan dalam fotografi. Karya fotografi juga memerlukan sentuhan dari nirmana karena nirmana merupakan ilmu yang mempelajari unsur-unsur tata rupa. Tujuan penelitian ini adalah menghasilkan karya-karya fotografi portraiture nirmana dengan teknologi 3D anaglyph. Dengan menggunakan metodologi eksperimental, penelitian ini mengeksplorasi teknik penciptaan fotografi 3D anaglyph. Luaran karya fotografi 3D tersebut menjadi bukti bahwa sisi estetis nirmana dan teknologi fotografi 3D anaglyph merupakan ilmu yang saling berhubungan dan implementatif satu sama lain secara khusus dengan ilmu fotografi.
\end{abstract}

Kata kunci : 3D anaglyph, fotografi, nirmana, portraiture

\begin{abstract}
The implementation of $3 D$ technology recently is more applicated in film and animation, whereas that technology has big potential to develop in photography, especially the $3 D$ photography genre. Until now, only a few photographers have focused on this genre and are interested in conducting further experiments. 3D photography still has the potential to be developed because 3D applications can produce unique photos. Photography is one of the science and technology fields, therefore photography should move dynamically in line with technological developments. Through research that leads to experimental photography and $3 D$ imagery is expected to contribute novelty in photography. Photographic work also requires nirmana touch because nirmana learns the elements of fine arts. The purpose of this research is to produce portraiture photography works of nirmana with anaglyph 3D technology. By using the experimental methodology, this study explores 3D anaglyph photography creation techniques. The output of $3 D$ photography is evidence that nirmana aesthetic and $3 D$ photography technology are interrelated and implementative especially with the science of photography.
\end{abstract}

Keywords : 3D anaglyph, photography, nirmana, portraiture 


\section{PENDAHULUAN}

Dalam perkembangan fotografi dewasa ini ada banyak genre yang populer di masyarakat seperti fotografi jurnalistik, human interest landscape, sport, fotografi periklanan, foto produk, foto model, foto fashion, foto wedding, dan lain sebagainya. Namun dari setiap genre yang begitu populer di masyarakat jarang mendengar ada genre fotografi 3D, karena selama ini implementasi teknologi 3D biasa digunakan di dunia perfilman dan animasi. Padahal fotografi 3D masih menyimpan potensi untuk dikembangkan karena aplikasi 3D dapat membuat media foto tersebut menjadi sangat unik. Fotografi merupakan salah satu dari IPTEKS (IImu Pengetahuan, Teknologi, dan Seni) yang sangat implementatif di kehidupan masyarakat modern, apalagi dengan perkembangan fotografi digital yang masif, fotografi saat ini menjadi sesuatu yang tidak pernah lepas dari para pengguna gawai. Oleh karena itu ilmu fotografi juga seharusnya bergerak dinamis mengikuti perkembangan IPTEKS, maka dengan penelitian yang mengarah pada eksperimental fotografi dan citra 3D diharapkan dapat memberikan kontribusi besar dalam kebaharuan keilmuan khususnya pada ranah fotografi.

Citra 3D anaglyph merupakan teknologi pencitraan tiga dimensi yang muncul dari penggabungan 2 citra 2D stereoscopik yang merepresentasikan penglihatan mata kanan dan kiri sehingga menciptakan ilusi visual 3D (Anggela, 2013). Pemilihan 3D anaglyph sebagai teknis yang akan di eksplorasi di penelitian ini dikarenakan teknik ini merupakan implementasi pencitraan 3D yang paling mudah diadaptasi di media cetak dan fotografi. 3D anaglyph bahkan bisa diadaptasi oleh model cetak grafis yang berbasis CMYK meskipun sebenarnya 3D anaglyph merupakan pemisahan channel warna RGB.

Sentuhan 3D anaglyph pada penciptaan karya fotografi akan meningkatkan nilai inovasi IPTEKS. Namun untuk lebih bernilai seni karya fotografi memerlukan sentuhan dari nirmana karena nirmana merupakan ilmu yang mempelajari unsur-unsur tata rupa. Dengan adanya implementasi nirmana pada fotografi maka karya dalam penelitian ini akan memiliki nilai estetis yang tinggi. Penelitian ini akan mewujudkan sebuah luaran berupa karya-karya fotografi portraiture nirmana namun dengan teknologi 3D anaglyph. Melalui proses penciptaan karya-karya tersebut peneliti akan bereksperimen mencari metode teknis yang tepat untuk menciptakan karya fotografi 3D anaglyph. Detail dari eksperimen tersebut akan mencari bagaimana proses pemisahan channel RGB pada karya fotografi, mencari jangkauan lensa yang tepat, proyeksi nirmana, skema penempatan lighting, dan lain-lain supaya mendapat citra 3D yang diinginkan. Luaran yang berupa karya fotografi 3D tersebut juga akan menjadi bukti bahwa antara sisi estetis nirmana dan sentuhan IPTEKS 3D anaglyph merupakan bidang ilmu yang saling berhubungan dan implementatif satu sama lain secara khusus dengan bidang fotografi.

\subsection{Nirmana sebagai Dasar Kemampuan Estetika Desain}

Menurut Sanyoto (2005), nirmana berasal dari bahasa Sansekerta "Nir" dan "Makna" yang berarti tanpa makna, atau kosong, tidak ada apa-apa. Nirmana merupakan dasar 
yang teramat penting dalam mempelajari seni rupa. Nirmana berbasis estetika dimana keindahan adalah tujuan utama mempelajari bidang ini. Sering kali kita melihat ada banyak fotografer atau seni rupawan yang menguasai teknis dengan sangat baik, namun dalam berkarya mereka tidak pernah menghasilkan karya-karya yang menarik. Hal ini disebabkan karena minimnya pengetahuan mengenai konsep estetika sendiri. Pada umumnya orang hanya membuat berdasarkan kemampuannya memegang kamera, namun mereka tidak pernah belajar bagaimana cara membuat foto yang enak dilihat oleh mata. Kemampuan teknis fotografi tentunya harus dipisah dengan kemampuan dalam menata sebuah gambar, karena walau dengan kemampuan teknis fotografi yang minim sekalipun, kita dapat membuat sebuah karya foto maupun obyek seni rupa yang menarik selama kita menguasai betul tentang dasar-dasar seni rupa dan desain.

Nirmana dapat memberi pengetahuan mengenai berbagai macam prinsip tata letak, diagram warna, etika desain, dan lain-lain yang merupakan dasar dari sebuah perancangan. Idealnya dalam mempelajari nirmana adalah menggunakan latihan yang bersifat manual/handmade. Hal tersebut dikarenakan dapat mempertajam insting visual, melatih telaten dan detail, menggunakan latihan manual juga akan membantu kita dalam mencari ciri khas dalam karya kita. Dalam nirmana kita akan mempelajari secara khusus mengenai berbagai macam prinsip tata rupa dan prinsip diagram warna. Sebuah desain merupakan pengorganisasian atas berbagai unsur seni rupa yaitu; titik, garis, bentuk, bidang, tekstur dan ruang.

\subsection{Fotografi Portraiture di Indonesia}

Fotografi portraiture adalah fotografi dari seorang tokoh atau sekelompok orang yang menyimpan ekspresi, kepribadian dan perasaan dari subyek tersebut. Sejarah fotografi portraiture di Indonesia dimulai pada tahun 1857, pada saat 2 orang juru foto Woodbury dan Page membuka sebuah studio foto di Harmonie, Batavia. Masuknya fotografi ke Indonesia tepat 18 tahun setelah Daguerre mengumumkan hasil penelitiannya yang kemudian disebut-sebut sebagai awal perkembangan fotografi komersil. Studio fotopun semakin ramai di Indonesia, dan salah satu pelopor fotografi portraiture di Indonesia adalah Kassian Cephas. (Segara, 2012)

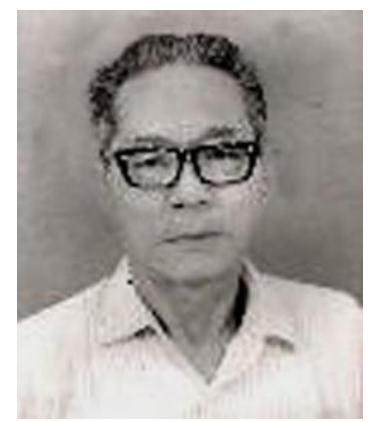

Gambar 1. Kassian Cephas (1844-1912)

[Sumber: https://slideplayer.info/slide/1963008/] 
Cephas lahir pada 15 Januari 1845 dari pasangan Kartodrono dan Minah. Cephas juga merupakan anak angkat dari orang Belanda yang bernama Frederik Bernard Fr. Schalk. Cephas menghabiskan masa kanak-kanaknya di rumah Christina Petronella Steven Cephas mulai belajar menjadi fotografer profesional pada tahun 1860-an, Kemudian magang di Isidore van Kinsbergen. Cephas bekerja di Jawa Tengah sekitar tahun 1863-1875. Berita kematian Cephas di tahun 1912 menyebutkan bahwa ia belajar fotografi kepada seseorang yang bernama Simon Willem Camerik. Nama Kassian Cephas mulai dikenal banyak orang saat memotret Sultan Hamengku Buwono VII muncul di tembok istana. Sejak saat itu Cephas dikenal sebagai pelopor fotografi portraiture di Indonesia.
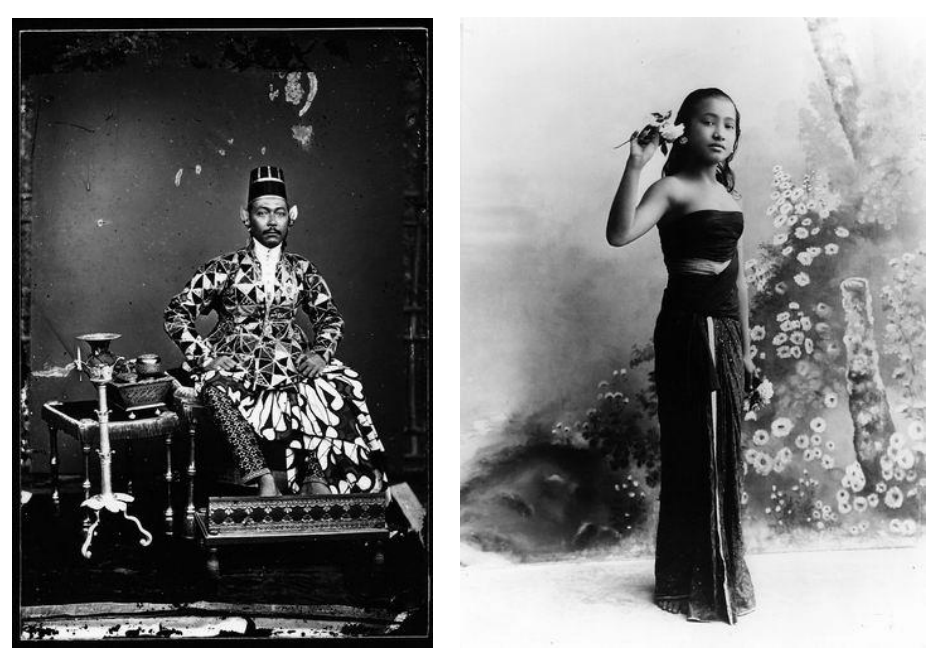

Gambar 2. Foto Portraiture Karya Cephas

(kiri) "Sultan Hamengku Buwono VII" dan (kanan) "Gadis Bali” [Sumber: https://slideplayer.info/slide/1963008/]

Dari foto-fotonya tersebut, bisa dibilang bahwa Cephas telah memotret banyak hal tentang kehidupan di dalam Keraton, mulai dari foto Sultan Hamengku Buwono VII dan keluarganya, bangunan-bangunan sekitar Keraton, upacara Garebeg di alun-alun, iring-iringan benda untuk keperluan upacara, tari-tarian, hingga pemandangan Kota Yogyakarta dan sekitarnya. Tidak itu saja, bahkan Cephas juga diketahui banyak memotret candi dan bangunan bersejarah lainnya, terutama yang ada di sekitar Yogyakarta. Namun dari banyak karya-karya fotografinya Cephas lebih banyak dikenal sebagai seorang fotografer portraiture karena karya-karyanya banyak menggunakan obyek manusia atau figur (Setyanto, 2017).

\subsection{Fotografi 3D Anaglyph}

Citra 3D (Three Dimensional) atau tiga dimensi adalah setiap objek yang memiliki tiga dimensi yaitu lebar, tinggi, dan kedalaman (width, height, dan depth). Dengan kata lain grafik 3D adalah grafik yang dipaparkan dalam bentuk 3 dimensi pada paksi atau koordinat $x, y$, dan $z$. Setiap obyek yang dibuat menggunakan software aplikasi 3D akan mempunyai dimensi seperti yang disebutkan di atas. (Arofa, 2017) 


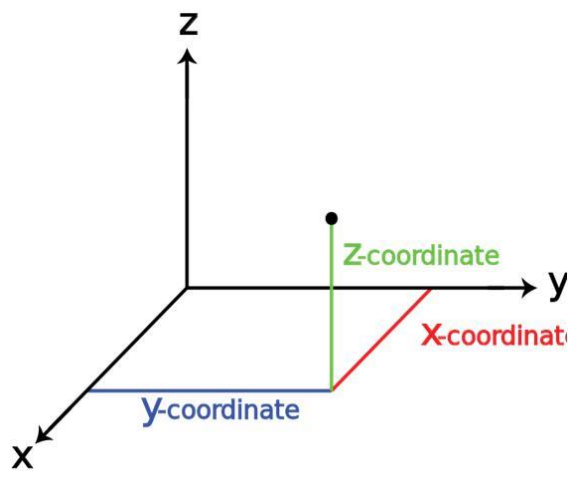

Gambar 3. Grafik XYZ pada Citra 3D

[Sumber: Arofa, 2017]

Membuat gambar tiga dimensi (perspektif) merupakan kegiatan menuangkan anganangan dalam ukuran tiga dimensi kedalam kertas dua dimensi, baik dengan pengamatan langsung atau berdasarkan kenyataan. Dalam gambar benda yang lebih dekat dengan mata akan tergambar lebih besar bila dibandingkan dengan yang jauh dengan mata. Semakin jauh dari pandangan mata semakin kecil dan akhirnya menghilang di titik horizontal. Sehingga citra 3D selalu memiliki persepsi jarak baik itu dipersepsikan dekat atau jauh. (Arofa, 2017)

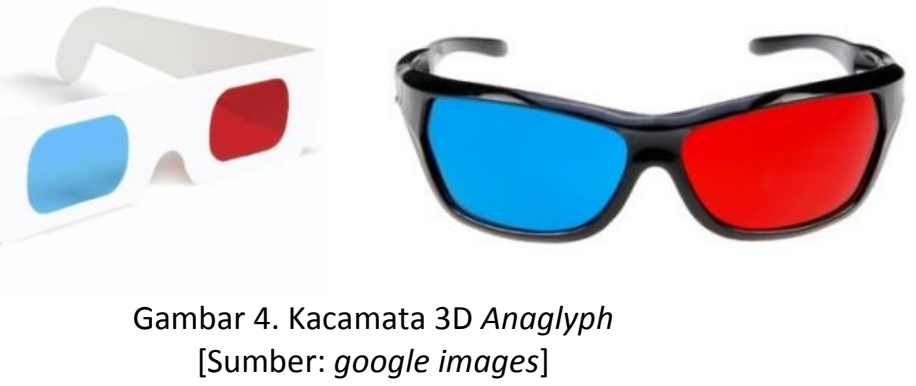

Dalam dunia sinematografi kita mengenal ada istilah citra 3D anaglyph atau teknologi visual yang memberikan efek stereoscopic pada penglihatan dengan mengencode gambar yang diterima setiap mata menggunakan filter warna (biasanya warna kromatik yang berlawanan) yaitu merah dan cyan (Anggela, 2013). Gambar anaglyph mengandung 2 gambar yang difilter dengan warna yang berbeda namun menyatu. Dengan melihat melalui color coded anaglyph glasses (kode warna kacamata anaglyph)setiap gambar akan diterima masing-masing mata (kiri dan kanan). Tujuannya memberikan persepsi tiga dimensi oleh visual cortex pada otak manusia, kejadian ini disebut brain fuses. Meskipun anaglyph adalah teknologi lama ditemukan oleh Wilhelm Rollmann pada tahun 1852. Namun anaglyph masih digunakan di zaman modern sebagai sarana hiburan dan pembelajaran dengan biaya operasional yang murah. Berikut penulis lampirkan contoh foto 3D anaglyph sebagai eksperimen awal sebelum penelitian ini dimulai. Dalam mempersiapkan penelitian ini, penulis telah melakukan beberapa eksperimen awal yang dapat menjadi gambaran akan wujud luaran karya yang nantinya dihasilkan dari penelitian ini. Eksperimen tersebut penulis lakukan dengan mengadakan dua sesi pemotretan yang menggambarkan akan dua jenis foto yaitu foto nirmana portraiture (merupakan 
aplikasi proyeksi gambar nirmana ke portraiture manusia) dan foto 3D anaglyph (merupakan penggabungan 2 citra steroescopic dari imaji mata kanan dan kiri).
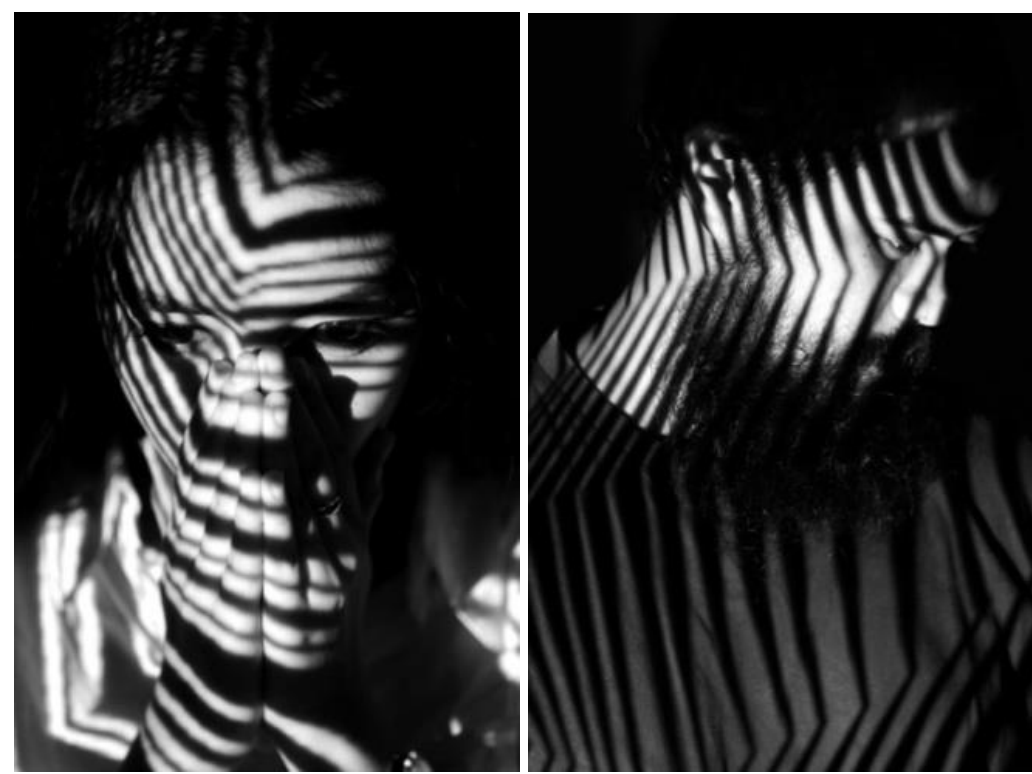

Gambar 5. Contoh Karya Foto Eksperimental Nirmana Portraiture [Sumber : Dokumentasi Penulis]

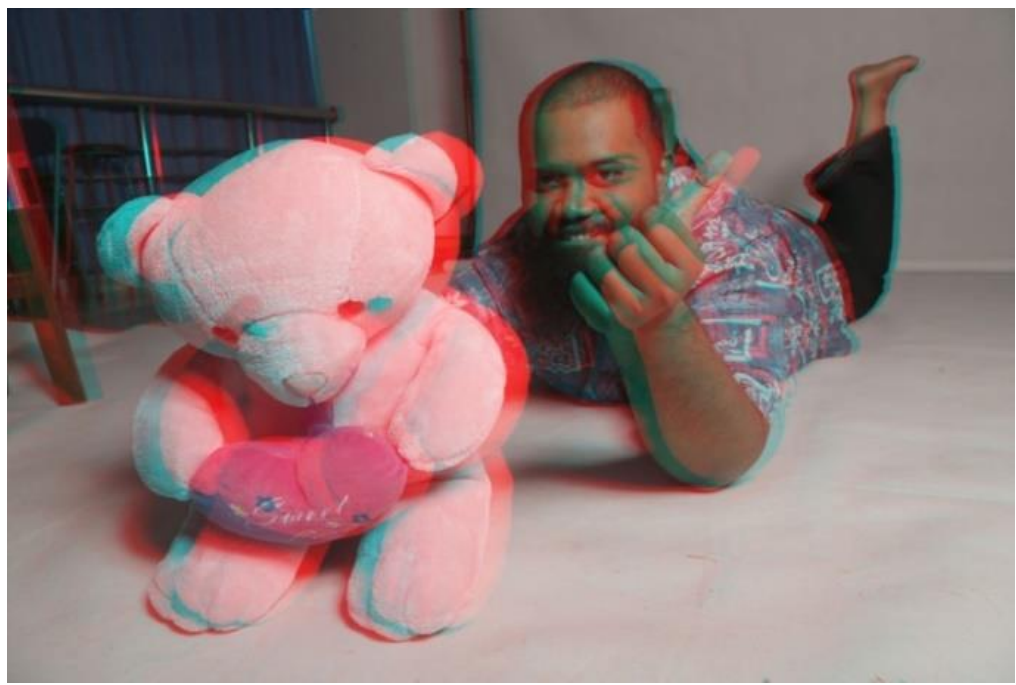

Gambar 6. Contoh Karya Eksperimental Foto 3D Anaglyph

(Gunakan Kacamata 3D untuk Hasil Imaji 3D yang Lebih Sempurna) [Sumber : Dokumentasi Penulis]

\section{METODE PENELITIAN}

Penelitian ini menggunakan metode eksperimental. Menurut Cochran (1957) mengartikan eksperimen sebagai sebuah atau sekumpulan percobaan yang dilakukan melalui perubahan-perubahan terencana terhadap variabel input suatu proses atau sistem sehingga dapat ditelusuri penyebab dan faktor-faktor sehingga membawa perubahan pada output sebagai respon dari eksperimen yang telah dilakukan. Adapun tujuan dari metode eksperimen adalah untuk menguji efektifitas dan efisiensi dari 
suatu pendekatan, metode, teknik, atau media pengajaran dan pembelajaran, sehingga hasilnya bisa diterapkan jika memang baik atau tidak digunakan jika memang tidak baik dalam pengajaran sebenarnya. Sedangkan menurut Nasir (1988: 75) mengemukakan tujuan dari penelitian eksperimental adalah untuk menyelidiki adatidaknya hubungan sebab akibat serta berapa besar hubungan sebab akibat tersebut dengan cara memberikan perlakuan-perlakuan tertentu pada beberapa kelompok eksperimental dan menyediakan kontrol perbandingan.

Dalam penelitian ini metode eksperimen dilakukan dengan cara mengeksplorasi teknik pemotretan agar menghasilkan karya fotografi portraiture 3D anaglyph yang terbaik. Variabel yang dieksplorasi bisa berupa bagan peletakan lighting, pengambilan sudut pemotretan, pemilihan focal lenght lensa, penggunaan alat serta jarak pengambilan. Eksperimen yang dilakukan terdiri dari 3 tahap yang yaitu eksperimen tahap 1 yang berfokus pada implementasi nirmana pada foto portraiture. Pada tahap 2 eksperimen akan berfokus pada proses pembuatan foto 3D anaglyph dan pada tahap 3 akan berfokus pada penggabungan karya fotografi portraiture nirmana dan implementasi fotografi 3D anaglyph.

\section{HASIL DAN PEMBAHASAN}

Penulis melakukan serangkaian eksperimental seputar teknis pemotretan untuk menghasilkan efek 3D anaglyph yang maksimal.

\subsection{Eksperimental Tahap 1}

Tahap awal eksperimental adalah membuat karya fotografi aplikasi nirmana repetisi hitam putih dan aplikasi nirmana tekstur warna pada portraiture model manusia seacra close up. Teknis foto yang digunakan tersebut akan digabungkan pada tahap berikutnya yaitu implementasi format 3D anaglyph. Tujuan dari eksperimental tahap 1 ini adalah memetakan pencapaian estetis penciptaan fotografi portraiture nirmana.

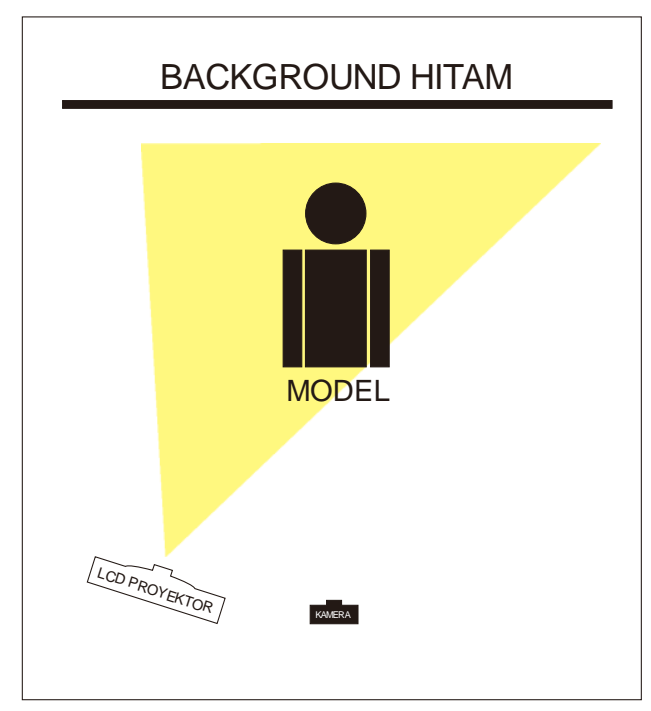

Gambar 7. Skema Lighting Setup untuk Foto Portraiture Nirmana

[Sumber : Dokumentasi Penulis] 
Eksperimen tahap 1 menggunakan penerangan LCD proyektor yang diarahkan kepada model secara langsung untuk mendapatkan proyeksi karya nirmana secara langsung pada wajah dan tubuh model yang akan di foto. Background yang digunakan adalah warna hitam untuk mengoptimalkan hasil proyeksi nirmana pada wajah dan sebagian tubuh model karena akan menimbulkan kontras yang kuat antara objek yang difoto dengan backgroundnya.
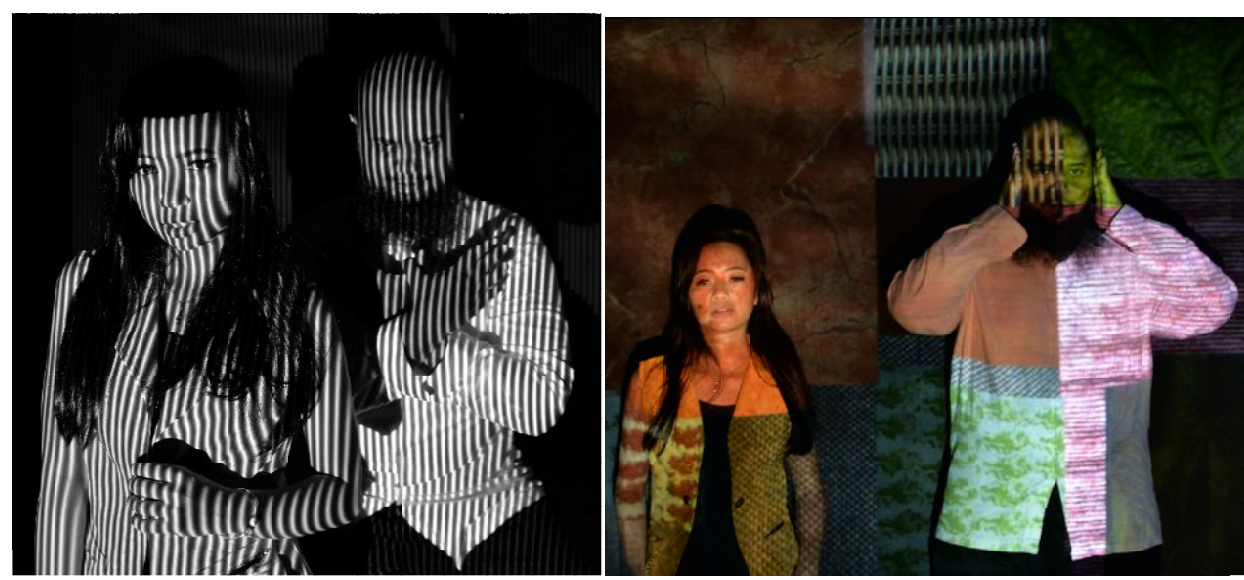

Gambar 8. (kiri) Hasil Eksperimental Fotografi Portraiture Nirmana Repetisi dan (kanan) Hasil Eksperimental Fotografi Portraiture Nirmana Tekstur. (talent: Arum dan Gilang).

[Sumber : Dokumentasi Penulis]

\subsection{Eksperimental Tahap 2}

Eksperimental tahap kedua akan mengeksplorasi pembuatan fotografi 3D anaglyph. Pada eksperimental ini peneliti tidak menggunakan kamera atau lensa 3D pabrikan namun menggunakan kamera DSLR dan lensa konvensional. Eksperimental tahap kedua ini cukup krusial karena mencari komposisi jarak yang paling efektif dalam penciptaan efek 3D anaglyph antara pemotretan versi mata kiri dan mata kanan. Jarak pemotretan mata kanan dan kiri ini juga berkorelasi terhadap jarak focal lenght pada lensa.

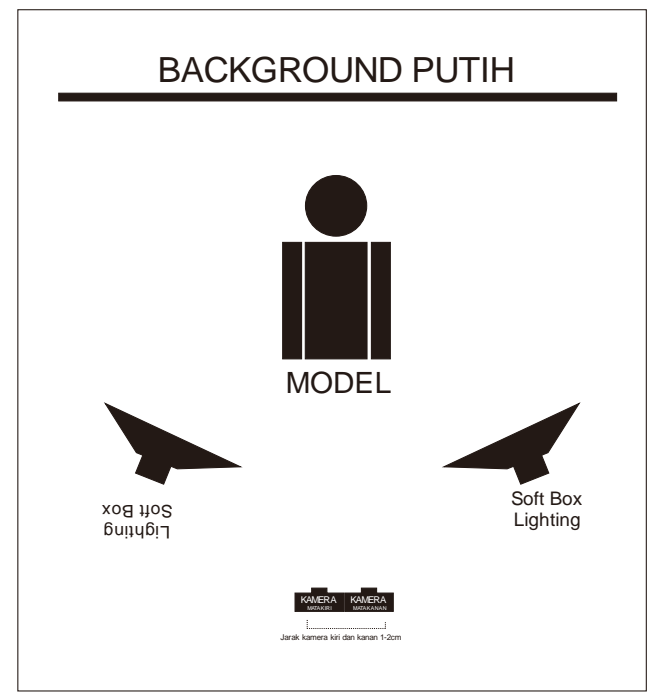

Gambar 9. Skema Lighting Setup Untuk Foto 3D Anaglyph

[Sumber : Dokumentasi Penulis] 
Pemotretan pada eksperimental tahap kedua ini menggunakan teknis pemotretan studio indoor dengan aksesoris softbox yang diletakkan kanan dan kiri dengan kekuatan cahaya sama besar untuk menghasilkan ketajaman yang optimal seperti terlihat pada gambar 9. Sedangkan untuk menghilangkan channel merah serta penggabungan foto mata kanan dan kiri dilakukan lewat software Adobe Photoshop. Eksperimen ini menggunakan berapa variabel uji coba. Variabel pertama adalah focal lengt (FL) yaitu lensa yang meliputi $\mathrm{FL} 16-24 \mathrm{~mm}, 24-35 \mathrm{~mm}, 35-85 \mathrm{~mm},>85 \mathrm{~mm}$. Variabel kedua adalah jarak pemotretan antara mata kanan dan kiri yaitu $0.5-1 \mathrm{~cm}, 1-$ $2 \mathrm{~cm}, 2-3 \mathrm{~cm}$ dan $3-4 \mathrm{~cm}$. Variabel ketiga adalah jarak fokus yaitu $0.5 \mathrm{~m}, 1 \mathrm{~m}, 2 \mathrm{~m}$ dan $4 \mathrm{~m}$. Dari hasil uji coba tersebut dapat diambil kesimpulan bahwa efek 3D anaglyph hanya bisa didapatkan dengan menggunakan lensa focal lenght lebar - medium antara 16$35 \mathrm{~mm}$ dengan jarak model dengan kamera antara 0.5-1 meter. Untuk detailnya hasil uji coba tersebut bisa dilihat di tabel dibawah ini:

Tabel 1. Tabel Jarak Focal Lenght untuk Foto 3D Anaglyph

[Sumber : Dokumentasi Penulis]

\begin{tabular}{|c|c|c|c|c|}
\hline $\begin{array}{l}\text { Jarak focal lenght } \\
\text { Lensa }(\mathrm{mm}) \text { dalam } \\
\text { format full frame }\end{array}$ & $\begin{array}{c}\text { Jarak pemotretan } \\
\text { antara mata kanan } \\
\text { dan kiri }\end{array}$ & $\begin{array}{l}\text { Jarak model } \\
\text { (portraiture). }\end{array}$ & Tripot & Hasil 3D \\
\hline \multirow{4}{*}{$16-24 \mathrm{~mm}$} & $0.5-1 \mathrm{~cm}$ & $0.5 \mathrm{~m}$ & $\checkmark$ & Berhasil \\
\hline & $1-2 \mathrm{~cm}$ & $1 \mathrm{~m}$ & $\checkmark$ & Berhasil \\
\hline & $2-3 \mathrm{~cm}$ & $2 \mathrm{~m}$ & $\checkmark$ & Tidak Berhasil \\
\hline & $3-4 c m$ & $4 m$ & $\checkmark$ & Tidak Berhasil \\
\hline \multirow{4}{*}{$25 m m-35 m m$} & $0.5-1 \mathrm{~cm}$ & $0.5 \mathrm{~m}$ & $\checkmark$ & Berhasil \\
\hline & $1-2 \mathrm{~cm}$ & $1 \mathrm{~m}$ & $\checkmark$ & Berhasil \\
\hline & $2-3 c m$ & $2 \mathrm{~m}$ & $\checkmark$ & Tidak Berhasil \\
\hline & $3-4 c m$ & $4 \mathrm{~m}$ & $\checkmark$ & Tidak Berhasil \\
\hline \multirow{4}{*}{$36 m m-85 m m$} & $0.5-1 \mathrm{~cm}$ & $0.5 \mathrm{~m}$ & $\checkmark$ & Tidak Berhasil \\
\hline & $1-2 \mathrm{~cm}$ & $1 \mathrm{~m}$ & $\checkmark$ & Tidak Berhasil \\
\hline & $2-3 \mathrm{~cm}$ & $2 \mathrm{~m}$ & $\checkmark$ & Tidak Berhasil \\
\hline & $3-4 c m$ & $4 \mathrm{~m}$ & $\checkmark$ & Tidak Berhasil \\
\hline \multirow{4}{*}{$>85 \mathrm{~mm}$} & $0.5-1 \mathrm{~cm}$ & $0.5 \mathrm{~m}$ & $\checkmark$ & Tidak Berhasil \\
\hline & $1-2 \mathrm{~cm}$ & $1 \mathrm{~m}$ & $\checkmark$ & Tidak Berhasil \\
\hline & $2-3 \mathrm{~cm}$ & $2 \mathrm{~m}$ & $\checkmark$ & Tidak Berhasil \\
\hline & $3-4 c m$ & $4 \mathrm{~m}$ & $\checkmark$ & Tidak Berhasil \\
\hline
\end{tabular}

Berikut adalah salah satu contoh foto hasil eksperimental tahap kedua yaitu pembuatan fotografi 3D anaglyph. Untuk mendapatkan sensasi 3D anaglyph hanya bisa didapat dengan melihat foto dengan kacamata 3D. 


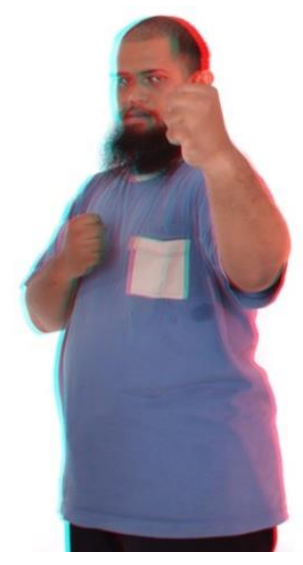

Gambar 10. Hasil Foto Eksperimental Tahap Kedua Menggunakan Focal Length 24 mm, Jarak Kamera Mata Kanan dan Kiri 1-2 cm, Jarak Model dengan Kamera 1-2 m.

[Sumber : Dokumentasi Penulis]

\subsection{Eksperimental Tahap 3}

Pada tahap ini dilakukan penggabungan dua metode sebelumnya yaitu pengaplikasian nirmana portraiture dan pengaplikasian 3D anaglyph. Pada tahap tiga peneliti mencoba melakukan beberapa eksperimental untuk mendapatkan hasil paling optimal untuk menghasilkan karya fotografi aplikasi nirmana pada fotografi 3D anaglyph.

\section{a. Blending Method}

Penggabungan secara digital imaging dengan software adobe photoshop. Tahap ini menggunakan penggabungan karya nirmana secara digital lewat teknik blending pada software Adobe Photoshop. Caranya adalah dengan menyiapkan karya foto yang telah berformat 3D anaglyph kemudian dengan adobe photoshop ditumpukkan dengan layer yang berisikan karya nirmana kemudian diberi efek transparan agar menyatu dengan karya foto portraiture 3D anaglyph yang ada di bawah layer tersebut. Hasilnya tidak terlalu maksimal karena efek 3D pada gambar nirmana kurang dapat memunculkan kesan 3D namun justru nampak flat dan tidak berdimensi.
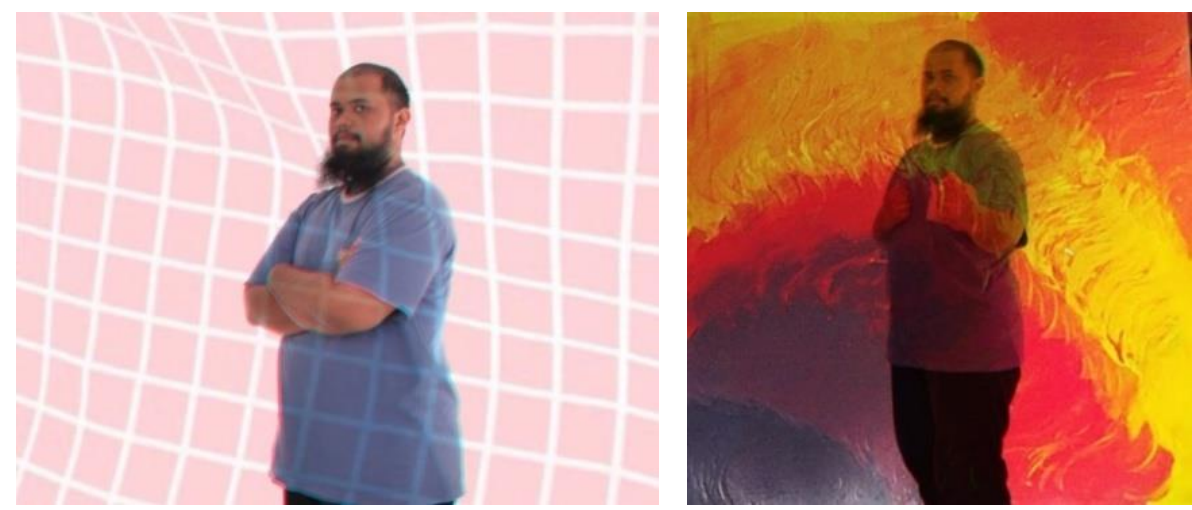

Gambar 11. Hasil Foto Eksperimental Tahap Ketiga Penggabungan Layer Gambar Nirmana Di Atas Foto Portraitureure yang Sudah Berformat 3D

[Sumber : Dokumentasi Penulis] 


\section{b. Projection Method}

Berbeda pada eksperimen sebelumnya, metode ini menggantikan metode layer blending dengan menggunakan proyeksi dari LCD Proyektor. Caranya adalah dengan menyorotkan gambar nirmana ke tubuh model dengan bantuan alat LCD Proyektor. Setelah itu difoto dengan representasi mata kiri dan kanan lalu digabungkan dengan software Adobe Photoshop untuk merubah ke format 3D anaglyph. Hasil dari eksperimen metode proyeksi ini menghasilkan karya yang cukup artistik namun dalam ketika diubah ke format 3D tidak optimal karena nirmana proyeksi tidak teraplikasi secara sempurna di tubuh model karena memunculkan bayanganbayangan yang mengganggu dari LCD proyektor. Berikut adalah hasil dari eksperimen metode proyeksi.

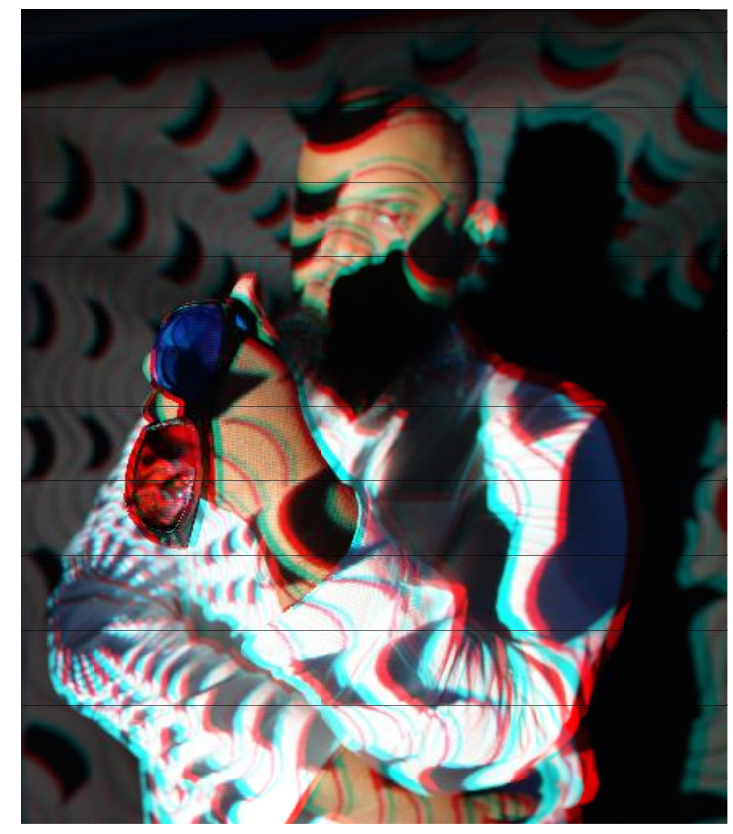

Gambar 12. Hasil Foto Eksperimental Tahap Ketiga dengan Metode Penyinaran LCD Proyektor.

[Sumber : Dokumentasi Penulis]

\section{c. Manual Drawing Method/Body Painting}

Metode ini adalah mengaplikasikan gambar nirmana secara manual ke tubuh model dengan cara melukis secara langsung ke wajah dan sebagian tubuh model. Setelah tubuh dan wajah model selesai dilukis, kemudian difoto menggunakan teknik low key atau latar belakang hitam supaya menghasilkan efek timbul pada objek yang difoto. 


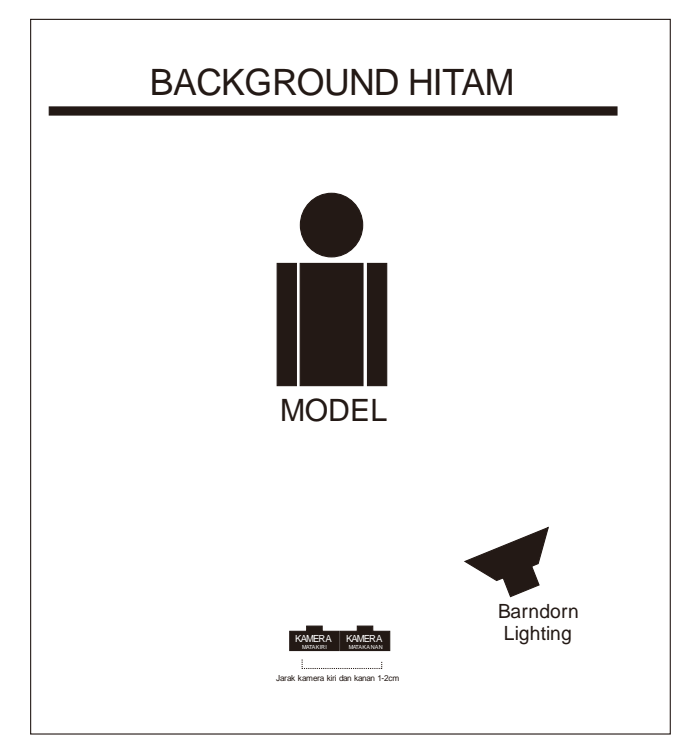

Gambar 13. Skema Lighting Setup untuk Foto 3D Anaglyph (Low Key)

[Sumber : Dokumentasi Penulis]

Proses convert 3D anaglyph dilakukan dengan cara mengambil 2 foto sebagai representasi mata kanan dan kiri kemudian digabungkan lewat software Adobe Photoshop. Hasil yang didapatkan dari metode manual drawing merupakan yang paling maksimal dari semua eksperimental yang telah dilakukan oleh peneliti, karena pada tahap ini segala kekurangan yang ada pada metode sebelumnya dapat diminimalkan seperti muncul bayangan-bayangan LCD proyektor yang akan mengganggu kesan 3 dimensional pada foto. Selain itu metode manual drawing ini dapat memunculkan kesan nirmana 3D anaglyph yang mendekati sempurna daripada metode yang lain. Satu-satunya kekurangan yang muncul pada metode manual drawing adalah munculnya distorsi warna sehingga warna yang muncul ketika dilihat menggunakan kacamata 3D tidak sama (meleset) dari warna aslinya. Berikut adalah hasil dari pemotretan eksperimental dengan metode manual drawing method/body painting. 


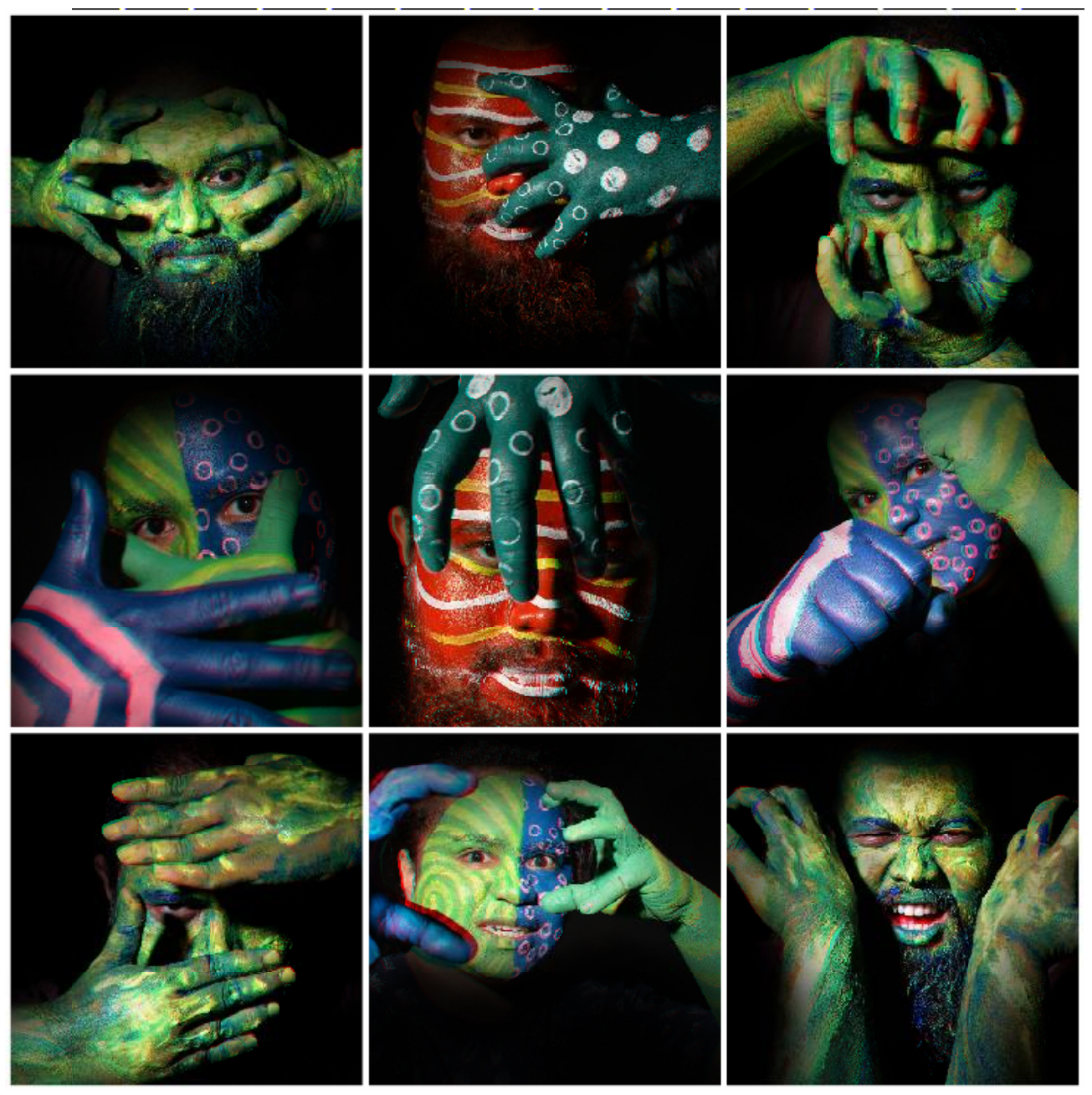

Gambar 14. Beberapa Hasil Foto Eksperimental Tahap Ketiga dengan Metode Manual Drawing / Body Painting.

[Sumber : Dokumentasi Penulis]

\section{KESIMPULAN}

Dari penelitian ini dapat disimpulkan bahwa untuk mendapatkan hasil fotografi 3D anaglyph yang sempurna fotografer sebaiknya menggunakan lensa dengan focal lenght lebar rentang $16-35 \mathrm{~mm}$ pada format kamera full frame. Hal tersebut diasumsikan karena pemotretan 3D anaglyph menggunakan representasi dari penglihatan mata kanan dan kiri yang paling mendekati rentang penglihatan mata manusia. Sedangkan untuk jarak fokus pemotretan untuk portraiture adalah antara $0.5 \mathrm{~m}-\infty$, oleh karena itulah pada hasil akhir dari pemotretan foto akan dicroping agar dapat menghasilkan foto portraiture yang tepat. Sedangkan untuk pengaturan kecepatan (speed) tidak berpengaruh pada hasil 3D anaglyph, namun untuk bukaan ( $f$ ) sebaiknya menggunakan diafragma sempit agar foto yang dihasilkan memiliki ruang tajam yang luas. Untuk aplikasi nirmana pada foto portraitureure 3D anaglyph juga dapat disimpulkan bahwa teknik aplikasi manual drawing/body painting adalah teknik aplikasi nirmana yang paling bagus atau sempurna dibandingkan dengan teknik lain seperti proyeksi LCD dan layer blending. Hanya saja teknik manual drawing atau body 
painting merupakan teknik yang memakan waktu paling lama daripada teknik yang lain karena harus melukis karya nirmana secara bertahap pada wajah dan tubuh model yang akan difoto.

Dengan ditemukannya rumusan atau metode pemotretan 3D anaglyph menggunakan lensa dan kamera konvensional maka semakin terbuka lebar peluang bagi penelitianpenelitian berikutnya di bidang penciptaan karya fotografi dengan menggunakan teknik serupa. Teknik 3D anaglyph ini dapat juga digunakan untuk penciptaan karya fotografi yang lain seperti halnya fotografi landscape, arsitektur, human interest dan fotografi abstrak atau ekspresi. Teknik 3D anaglyph juga mudah diadaptasi di berbagai media cetak, selain media RGB, teknik 3D anaglyph juga bisa digunakan pada media cetak CMYK sehingga bebas menggunakan jenis kertas apapun selama masih berformat full color.

Saran terpenting dari penelitian ini adalah berkaitan dengan publikasi cetak yang berformat hitam-putih sehingga karya fotografi 3D anaglyph tidak dapat dinikmati, karena untuk dapat menikmati karya foto ini 3D secara optimal harus dilihat dalam format berwarna dengan kacamata khusus. Tanpa hal tersebut karya fotografi 3D anaglyph menjadi sia-sia karena penyajian dengan format hitam putih hanya akan membuatnya nampak seperti foto konvensional, menikmati foto ini meskipun dalam format berwarna namun tanpa kacamata 3D juga hanya membuatnya tampak seperti sebuah karya abstrak yang memiliki distorsi warna.

\section{DAFTAR PUSTAKA}

Anggela, D. 2013. Perancangan Aplikasi Anaglyph Image dengan Menggunakan Metode Chromatic Anaglyphic pada Citra Berdasarkan Besarnya Jarak Pergeseran Warna. Jurnal Sistem dan Teknologi Informasi (JustIN), 1(3), 182-185.

Arofa, V. S. 2017. 1 Karakteristik Obyek 3 Dimensi. URL: www.scribd.com/document/336959987/1-Karakteristik-Obyek-3-Dimensi

[Diakses pada 10 April 2018]

Cochran, W.G. 1977. Sampling Method. Jhon Welley \& Son, INC

Nasir, Moh. 1988. Metode Penelitian. Jakarta: GI Press

Sanyoto, Sadjiman Ebdi. 2005. Dasar-Dasar Tata Rupa dan Desain (NIRMANA). Jogjakarta: Arti Bumi Intaran

Segara, T. M. 2012. Landasan Konseptual Perencanaan Dan Perancangan Akademi Dan Galeri Fotografi Di Yogyakarta Berdasarkan Pendekatan Arsitektur Metafora (Doctoral dissertation, UAJY).

Setyanto, Daniar Wikan. 2017. Perancangan Fotografi Esai "Semarang City By The Sea" Dengan Pendekatan EDFAT. Jurnal Andharupa, (03/02), 204-212.

Smith, Brian. 2007. Secrets of Great Portait Photography. Elex Media Komputindo 